\title{
Neither ACEls nor ARBs are associated with respiratory distress or mortality in COVID-19 results of a prospective study on a hospital-based cohort
}

\author{
Gian Paolo Anzola ${ }^{1}$ (1) . Clara Bartolaminelli ${ }^{2} \cdot$ Gina Alessandra Gregorini $^{3} \cdot$ Chiara Coazzoli $^{2} \cdot$ Francesca Gatti $^{4}$. \\ Alessandra Mora ${ }^{4}$. Dimitrios Charalampakis ${ }^{4}$. Andrea Palmigiano ${ }^{4} \cdot$ Michele De Simone $^{4} \cdot$ Alice Comini $^{4}$. \\ Erica Dellaglio ${ }^{4} \cdot$ Salvatore Cassetti ${ }^{4} \cdot$ Maurizio Chiesa $^{4} \cdot$ Francesca Spedini $^{4} \cdot$ Patrizia d'Ottavi $^{2}$. \\ Maria Cristina Savio ${ }^{4}$
}

Received: 7 July 2020 / Accepted: 5 September 2020 / Published online: 23 September 2020

(c) Società Italiana di Medicina Interna (SIMI) 2020

\begin{abstract}
Considerable concern has emerged for the potential harm in the use of angiotensin-converting enzyme inhibitors (ACEIs) and angiotensin receptor inhibitors (ARBs) in COVID-19 patients, given that ACEIs and ARBs may increase the expression of ACE2 receptors that represent the way for coronavirus 2 to entry into the cell and cause severe acute respiratory syndrome. Assess the effect of ACEI/ARBs on outcome in COVID-19 patients. Hospital-based prospective study. A total of 431 patients consecutively presenting at the Emergency Department and found to be affected by COVID-19 were assessed. Relevant clinical and laboratory variables were recorded, focusing on the type of current anti hypertensive treatment. Outcome variables were NO, MILD, SEVERE respiratory distress (RD) operationally defined and DEATH. Hypertension was the single most frequent comorbidity $(221 / 431=51 \%)$. Distribution of antihypertensive treatment was: ACEIs $77 / 221(35 \%)$, ARBs 63/221 (28\%), OTHER than ACEIs or ARBs 64/221 (29\%). In 17/221 (8\%) antihypertensive medication was unknown. The proportion of patients taking ACEIs, ARBs or OTHERs who developed MILD or SEVERE RD was 43/77 (56\%), 33/53 (52\%), 39/64 (61\%) and 19/77 (25\%), 16/63 (25\%) and 16/64 (25\%), respectively, with no statistical difference between groups. Despite producing a RR for SEVERE RD of 2.59 (95\% CI 1.93-3.49), hypertension was no longer significant in a logistic regression analysis that identified age, CRP and creatinine as the sole independent predictors of SEVERE RD and DEATH. ACEIs and ARBs do not promote a more severe outcome of COVID-19. There is no reason why they should be withheld in affected patients.
\end{abstract}

Keywords COVID-19 · Angiotensin converting enzyme inhibitor · Angiotensin receptor blocker

\section{Introduction and aim of the study}

In early December 2019, a new pathogen, later identified as a novel enveloped RNA betacoronavirus, that is currently been named severe acute respiratory syndrome coronavirus (SARS-CoV-2), gave rise to an outbreak of pneumonia that

Gian Paolo Anzola

gpanzola@gmail.com

1 San Camillo Hospital, via Turati 47 25123, Brescia, Italy

2 Azienda Territoriale Sanitaria (Territorial Health Authority), Brescia, Italy

3 University of Brescia, Brescia, Italy

4 Emergency Department Gavardo Hospital, Brescia, Italy started from Wuhan in the Chinese province of Hubei and spread across a large territory of the country infecting more than 80,000 subjects in less than a couple of months [1]. Despite the lack of a proven specific treatment, the infection was readily contained and limited mainly through stringent social distancing and quarantine, but before being able to close the borders, an unknown number of probably asymptomatic patients let the virus spread all over the world. Italy was among the first European countries to be affected. The first case was reported by media on February 21 as being hospitalized in Codogno in the Lombardia Region (Northern Italy). Henceforth, the surge of epidemics has followed an exponential rise that only recently has somehow flattened, with a cumulative prevalence of infected cases beyond 240,000 individuals, more than 34,000 cumulative deaths 
and a number of newly diagnosed cases that is still around 250 a day according to the WHO published report as to July 4 (https://www.who.int/emergencies/diseases/novel-coron avirus-2019/situation-reports).

SARS-CoV-2 has a phylogenetic similarity to SARS$\mathrm{CoV}$, responsible for the preceding 2002-2003 outbreak in China, with which it shares the propensity to attack the respiratory tract and cause a severe acute respiratory syndrome. Despite being probably less lethal than SARS, which had a reported case fatally rate of $43 \cdot 3 \%(35 \cdot 2-52 \cdot 4)$ in patients aged 60 years or older [2], current coronavirus disease 19 (COVID-19) is not at all a benign disease. Since the first reports from Chinese Authors, it has become clear that some variables such as male gender, cardiovascular disease, advanced age and hypertension may drastically worsen the prognosis [3-5]. In particular hypertension has become the focus of a warm debate on the use of angiotensin-converting enzyme (ACE) inhibitors (ACEIs) and angiotensin receptor inhibitors (ARB), which have established for a long time a mainstay in the treatment of hypertension [6-8]. The main reason of apprehension resides in the fact that ACE2 receptors, which belong to the renin-angiotensin system and are widely represented in many organs, including pulmonary alveoli, represent the way for coronavirus 2 (SARS-CoV-2) to entry into the cell. Since some laboratory data suggest that long lasting use of ACEIs or ARBs may upregulate ACE 2 receptors, considerable concern has emerged for the potential harm in their use as they might cause an increased susceptibility to viral penetration into the respiratory cells and give way to a more serious disease [6-10].

Partly to help solving this issue, we undertook a prospective study aimed at assessing the clinical characteristics, with particular emphasis on the type of antihypertensive medication, of all consecutive patients presenting at the Emergency Department of a Community Hospital in Gavardo, in the neighborhood of Brescia in Lombardia (Italy), and found to be positive for SARS-CoV-2 infection.

\section{Material and method}

The place of recruitment was the Emergency Department of the Hospital of Gavardo, situated in the neighborhood of Brescia in Lombardia and belonging to the Local Health Authority (LHA) ASST Garda.

This LHA serves a territory of about 2000 square kilometers on the western border of the lake of Garda with a population of about 380,000 inhabitants. These are evenly distributed between the three Community Hospitals located in the cities of Gavardo, Desenzano and Manerbio. Therefore the estimated catchment area of the Gavardo Hospital is about 126,000 people.
All consecutive patients presenting at the Emergency Department for symptoms or signs suggestive of SARSCoV-2 infection were considered for the study, but only those confirmed by real-time RT-PCR in nasal or pharyngeal swab were included.

On admission, a structured interview assessed demographic, anthropometric variables when possible and comorbidity. In particular a dichotomous categorization (yes/no) was employed for ischemic heart disease (including history of myocardial infarction, percutaneous transcatheter coronary angioplasty, coronary artery by-bass grafting), heart failure (present or past), stroke, atrial fibrillation, chronic renal failure, chronic liver disease, diabetes mellitus, chronic obstructive pulmonary disease (COPD), history of or present neoplasm, history of or present autoimmune disease, hypertension, current use of ACEIs, current use of ARBs, current use of antihypertensives other than ACEIs or ARBs (OTHERs). Relevant laboratory tests were recorded at presentation: these included hemoglobin $(\mathrm{Hb})$ in $\mathrm{g} / \mathrm{lt}$, platelet, leukocyte and lymphocyte count per microliter, serum creatinine in $\mathrm{mg} / \mathrm{dl}$, aspartate aminotransferase (AST), alanine aminotransferase (ALT) in units per liter and C-reactive protein (CRP) in $\mathrm{mg} / \mathrm{liter}$. In case of missing data, the electronic chart was reviewed on discharge to complete ascertainment.

Duration of symptoms from onset to presentation and cutaneous temperature were also recorded.

Dichotomous outcome variables were hospitalization, imaging evidence of lung infiltrates [11] and being dead or alive at the end of the hospital stay. Clinical severity was categorized as: $\mathrm{NO}$ respiratory distress $(\mathrm{NO} \mathrm{RD}=$ Sat. $\mathrm{O} 2>92 \%$ and no shortness of breath), MILD respiratory distress (MILD RD $=$ Sat. O2 $\leq 92 \%$, or shortness of breath or need for non-invasive ventilation, no need of invasive mechanical ventilation), and SEVERE respiratory distress (SEVERE RD = need of invasive mechanical ventilation).

Due to the often dramatic clinical emergency, some variables were incompletely assessed in a non-significant proportion of patients except for BMI that was available in only 195/431 (45\%).

The prevalence of each categorical variable and the means of continuous variables were calculated in patients with NO, MILD or SEVERE RD and in deceased subjects. In discharged patients, the clinical state was assessed after a mean of $15 \pm 3$ days by telephone call.

Single comparisons were performed with Chi-square test or Fisher's exact test when appropriate on categorical variables and with independent sample $t$ test (if normally distributed) or with Mann-Whitney $U$ test on continuous variables. For multiple comparisons of continuous variables, univariate ANOVA was used. Variables that had proved significant on univariate analysis were entered multivariate binomial logistic regression analyses to identify independent predictors of MILD RD, SEVERE RD and DEATH. Statistical 
significance was set at $p<0.05$. SPSS 20 statistical package was used. Findings on death are only partially reported as they will thoroughly be dealt with in a separate paper.

The study was approved by the Local Institutional Review Board.

\section{Results}

From March 12, 2020, to April 11, 2020, the study enrolled 431 patients $(\mathrm{M} / \mathrm{F}=263 / 168$, mean age $65 \pm 16$, range 16-95). Imaging was positive for lung infiltration in 347 (80\%) patients. 265 (62\%) were hospitalized. Mean duration of symptoms and temperature at presentation were $7 \pm 4$ days and $37.6 \pm 1^{\circ} \mathrm{C}$, respectively.

The prevalence of NO RD, MILD RD or SEVERE RD was $151 / 431(35 \%), 199 / 431(46 \%)$ and 81/431 (19\%), respectively. Case fatality rate (CFR) was 72/431 (17\%). In the whole cohort, comorbidity was distributed as follows: ischemic heart disease 50/431 (12\%), heart failure 18/431 (4\%), stroke 11/431 (3\%), atrial fibrillation 12/431 (3\%), chronic renal failure $16 / 431$ (4\%), chronic liver disease 4/431 (1\%), diabetes mellitus 60/431 (14\%), COPD 38/431 (9\%), history of or present neoplasm $37 / 431(9 \%)$, history of or present autoimmune disease 24/431 (6\%), and hypertension 221/431 (51\%). Current use of ACEIs was recorded in 77/221 (35\%), of ARBs in 63/221 (28\%) and of OTHERs in 64/221 (29\%) patients. In 17/221 (8\%) patients, it was impossible to establish the type of antihypertensive treatment.

For comparisons between outcomes, the composite cardiovascular disease (CVD) variable was created including any among: ischemic heart disease, heart failure, stroke, and atrial fibrillation. For some continuous variables, the proportion of patients exceeding the cutoff lab was also calculated in the four outcome groups.

Compared with those with NO RD, age, BMI, CVD, diabetes, hypertension, Sat. O2\%, lymphocyte count, creatinine, proportion of AST $\geq 32$, of creatinine $\geq 1.00$ (lab cutoff) and CRP were statistically different both in MILD and in SEVERE RD patients (Tables 1,2). Males were almost twice the number of females in both MILD RD and SEVERE RD groups. For AST and chronic renal failure, the difference from NO RD was significant only in SEVERE RD patients (Table 1). The impact of significant variables on outcome is expressed as relative risk, compared to NO $\mathrm{RD}$, in Table 2 .

Some variables were able to discriminate also MILD from SEVERE RD: these were age $(67 \pm 13$ vs. $78 \pm 11)$, CVD ( $18 \%$ vs. $42 \%)$, creatinine ( $1.04 \pm 0.46$ vs. $1.71 \pm 1.26)$ and CRP $(96 \pm 70$ vs. $152 \pm 83)$. Two ROC curves were fitted to CRP and creatinine values with SEVERE RD as outcome of interest. The area under the curve was 0.942 for CRP and
0.831 for creatinine. For CRP, the threshold value of 77.5 correctly identified $87 \%$ of SEVERE RD cases with $11.8 \%$ of false positives, whereas for creatinine the threshold value of 1.05 was less efficient as it picked up only $69.6 \%$ of cases with $8.8 \%$ of false positives.

The proportion of patients taking ACEIs, ARBs or OTHERs who developed MILD RD or SEVERE RD was 43/77 (56\%), 33/53 (52\%), 39/64 (61\%) and 19/77 (25\%), 16/63 (25\%) and 16/64 (25\%), respectively, with no statistical difference between groups (Fig. 1). Likewise, the proportion of patients treated with ACEIs, ARBs and OTHER antihypertensives was roughly the same (around 20\%) and constant within and across each class of severity ( Table 1).

Three multivariate logistic regression analyses were performed, with MILD RD, SEVERE RD and DEATH as dependent variables and taking as covariates those that had turned significant predictors in univariate analysis. The final model performed rather well, being able to predict $80.2 \%$ of cases in MILD RD, 92.1\% in SEVERE RD and 89.6\% in DEATH (Tables 3, 4, 5). Age and CRP were independent predictor of MILD RD, SEVERE RD and DEATH, AST only of MILD RD and creatinine of SEVERE RD and DEATH. In none of the three analyses was hypertension any longer significant.

\section{Discussion}

Since the very beginning of the outbreak of COVID-19, it has become clear that hypertension is the most represented comorbid condition in affected patients [12], with a reported prevalence ranging from 30 to $40.8 \%$ in China [13, 14] and 49\% in Italy [15]. Moreover, in univariate analyses hypertensive patients appear to be more likely to develop acute respiratory distress syndrome $[5,8]$, to be admitted in intensive care units $[1,8]$ or to die $[1,3,5]$, although this effect may become no more significant when corrected by age $[3,14]$. From many authorities, it has been suggested that taking ACEIs or ARBs may amplify the expression of ACE2 receptors that represent the way for SARS-CoV-2 to entry the respiratory cells and are widely represented in the alveolar cells, thus promoting the spreading of viral particles from upper to lower respiratory tract [6-10, 16-18]. However, the evidence for an increased activation of ACE2 from ACEIs and ARBs is far from being conclusive and moreover it may differ according to organ and ACEI type [6]. Furthermore, ACE2 over expression has paradoxically been claimed to be potentially beneficial because it raises levels of Angiotensin-(1-7) which is increasingly recognized to have organ-protective properties [8, 19-21]. To further complicate matters, ARBS are believed to directly inhibit Angiotensin II-induced inflammation and acute injury in the lungs [6]. 
Table 1 Demographic, clinical and laboratory findings in No RD, mild RD and severe RD patients

\begin{tabular}{|c|c|c|c|c|c|}
\hline & Total $(n=431)$ & $\begin{array}{l}\text { A } \\
\text { No }(n=151)\end{array}$ & $\begin{array}{l}\text { B } \\
\text { Mild }(n=199)\end{array}$ & $\begin{array}{l}\text { C } \\
\text { Severe }(n=81)\end{array}$ & $p$ \\
\hline Age (years) & $65(16)$ & $54(15)$ & 67 (13) & 78 (11) & $<.001^{*}$ \\
\hline Age $\geq 70$ & $179(41)$ & $23(15)$ & $91(46)$ & $65(82)$ & $<.001^{*}$ \\
\hline Female & $168(39)$ & $72(48)$ & $71(36)$ & $25(31)$ & $<.05^{\wedge}$ \\
\hline Male & 263 (61) & $79(52)$ & $128(64)$ & $56(69)$ & \\
\hline BMI & $28(6)$ & $26(4)$ & $30(6)$ & $30(6)$ & $<.005^{\wedge}$ \\
\hline $\mathrm{BMI} \geq 30$ & $48(27)$ & $13(14)$ & $23(36)$ & $12(46)$ & $<.005^{\wedge}$ \\
\hline Diabetes & $60(14)$ & $8(5)$ & $33(17)$ & $19(24)$ & $<.001^{\wedge}$ \\
\hline Hypertension & $221(51)$ & $41(27)$ & $123(62)$ & $57(70)$ & $<.001^{\wedge}$ \\
\hline ACEI & $77(35)$ & $15(10)$ & $43(22)$ & $19(23)$ & n.s \\
\hline $\mathrm{ARB}$ & $63(28)$ & $14(9)$ & $33(16)$ & $16(20)$ & n.s \\
\hline Other & 64(29) & $9(6)$ & $39(20)$ & $15(18)$ & n.s \\
\hline Chronic renal failure & $16(4)$ & $1(0.6)$ & $6(3)$ & $9(11)$ & $<.001-$ \\
\hline Creatinine $\geq 1$ & $130(30)$ & $14(10)$ & $61(31)$ & $55(68)$ & $<.001^{*}$ \\
\hline COPD & $39(9)$ & $12(8)$ & $14(7)$ & $12(15)$ & n.s \\
\hline Chronic liver disease & $4(1)$ & 0 & $3(2)$ & $1(1)$ & n.s \\
\hline Neoplasm & $37(9)$ & $8(5)$ & $22(11)$ & $7(9)$ & n.s \\
\hline Autoimmune disease & $24(6)$ & $8(5)$ & $3(2)$ & $3(4)$ & n.s \\
\hline Ischemic heart disease & $50(12)$ & $5(3)$ & $19(10)$ & $2632)$ & $<.05^{*}$ \\
\hline Heart failure & $18(4)$ & $2(1)$ & $10(5)$ & $6(7)$ & $<.001$ \\
\hline $\mathrm{AF}$ & $12(3)$ & $1(0.6)$ & $8(4)$ & $3(4)$ & n.s \\
\hline Stroke & $11(3)$ & 0 & $7(4)$ & $4(5)$ & n.s. \\
\hline CVD (composite) & $77(18)$ & $7(5)$ & $36(18)$ & $34(42)$ & $<.001^{*}$ \\
\hline Duration of sympt. (days) & $7(4)$ & $7(4)$ & $8(4)$ & $6(3)$ & n.s \\
\hline Axillary temperature & $37.6(1)$ & $37.3(1)$ & $37.7(1)$ & $37.5(1)$ & n.s \\
\hline Sat. $\mathrm{O}_{2} \%$ & $92(8)$ & $97(2)$ & $90(6)$ & $83(12)$ & $<.001^{*}$ \\
\hline $\mathrm{Hb}(\mathrm{g} / \mathrm{lt})$ & $14(2)$ & $14(2)$ & $14(2)$ & $14(2)$ & $\mathrm{n} . \mathrm{s}$ \\
\hline Platelet count $\left(\mathrm{mm}^{3}\right)$ & $200,000(74,000)$ & $196,000(81,000)$ & $204,000(81,000)$ & $195,000(74,000)$ & n.s \\
\hline Leukocyte count $\left(\mathrm{mm}^{3}\right)$ & 7045 (6769) & $6290(10,600)$ & $7041(3003)$ & $8440(3890)$ & n.s \\
\hline Lymphocyte count $\left(\mathrm{mm}^{3}\right)$ & $1103(625)$ & $1386(753)$ & $964(466)$ & $924(525)$ & $<.001^{\wedge}$ \\
\hline Lymphocyte $\leq 1100$ & $246(57)$ & $52(34)$ & $136(68)$ & $58(72)$ & $<.001^{\wedge}$ \\
\hline Creatinine (mg/dl) & $1.09(0.7)$ & $0.82(0.2)$ & $1.04(0.5)$ & $1.71(1.3)$ & $<.05^{*}$ \\
\hline $\operatorname{AST}(\mathrm{u} / \mathrm{lt})$ & $60(276)$ & $33(19)$ & $80(32)$ & $131(27)$ & $<.001^{\S}$ \\
\hline $\mathrm{AST} \geq 32$ & $258(60)$ & $50(34)$ & $144(73)$ & $64(1)$ & $<.001^{\wedge}$ \\
\hline $\operatorname{ALT}(\mathrm{u} / \mathrm{lt})$ & $40(81)$ & $28(17)$ & $40(32)$ & $58(180)$ & $<0.05 \S$ \\
\hline $\mathrm{ALT} \geq 25$ & $185(43)$ & $67(44)$ & $118(59)$ & $43(53)$ & $<.05^{\complement}$ \\
\hline CRP (mg/lt) & $84(77)$ & $31(38)$ & $96(70)$ & $152(83)$ & $<.001^{*}$ \\
\hline
\end{tabular}

DATA shows mean (sd) for continuous or $n(\%)$ for categorical variables

$N O$ no respiratory distress, MILD mild respiratory distress, SEVERE severe respiratory distress, $B M I$ Body Mass Index (weight/height ${ }^{2}$ ), $A C E I$ angiotensin-converting enzyme inhibitor, $A R B$ angiotensin receptor inhibitor, $C O P D$ chronic obstructive pulmonary disease, $A F$ atrial fibrillation, $C V D$ cardio vascular disease (any among ischemic heart disease, heart failure, AF, stroke), Sat. O2\% blood oxygen saturation, OTHER antihypertensive other than ACEI or ARB, AST aspartate aminotransferase, $A L T$ alanine aminotransferase, $C P R$ C-reactive protein

${ }^{*}$ A vs. B significant, A vs. C significant, B vs. C significant

${ }^{\wedge} \mathrm{A}$ vs. B significant, A vs. C significant, B vs. C n.s

${ }^{\S}$ A vs. B n.s., A vs. C significant, B vs. C n.s

${ }^{\mathrm{C}} \mathrm{A}$ vs. B significant, A vs. C n.s., B vs. C significant

Therefore, there is much uncertainty as to whether ACEIs and ARBs do really interfere with SARS-COV-2 aggressiveness and only clinically driven conclusions may definitely settle the question. This was the main reason for undertaking the present study. In the consecutive series of 431 proven COVID-19 patients enrolled in one month period, 
Table 2 The impact of significant variables on outcome expressed as relative risk (confidence interval) in univariate analysis

Fig. 1 Proportion of type of outcome per class of treatment. $N O$ no respiratory distress, $M I L D$ mild respiratory distress, SEVERE severe respiratory distress, Figures represent no. of patients. Height of each colored box represents the relative contribution to the total

Table 3 Logistic regression analysis taking MILD RD as dependent variable

\begin{tabular}{lllll}
\hline & MILD RD & $p$ & SEVERE RD & $p$ \\
\hline Age $\geq 70$ & $2.99(1.99-4.48)$ & $<.0001$ & $5.16(3.49-7.63)$ & $<.0001$ \\
Male sex (vs female) & $1.23(1.02-1.48)$ & $=.02$ & $1.79(1.42-2.24)$ & $<.0001$ \\
BMI $\geq 30$ & $2.7(1.50-4.85$ & $=.0006$ & $3.46(1.82-6.57)$ & .0002 \\
CVD (composite) & $3.9(1.79-8.53)$ & $=.0001$ & $9.05(4.20-19.51)$ & $<.0001$ \\
Diabetes & $3.13(1.49-6.58)$ & $=.0011$ & $4.43(2.03-9.67)$ & $<.0001$ \\
Hypertension & $2.28(1.72-3.02)$ & $<.0001$ & $2.59(1.93-3.49)$ & $<.0001$ \\
Chronic renal failure & $4.55(0.55-37.42)$ & n.s & $16.78(2.16-130.11)$ & .0002 \\
Creatinine $\geq 1$ & $3.49(1.99-6.11)$ & $<.0001$ & $7.93(4.62-13.59)$ & $<.0001$ \\
Ischemic heart disease & $2.88(1.10-7.55)$ & n.s & $9.69(3.87-24.28)$ & $<.0001$ \\
Heart failure & $3.79(0.84-17.06)$ & n.s & $5.59(1.15-27.8)$ & 0.0155 \\
Lymphocyte $\leq 1100 \mathrm{~mm}^{3}$ & $1.86(1.47-2.35)$ & $<.0001$ & $2.00(1.56-2.57)$ & $<.0001$ \\
AST $\geq 32 \mathrm{u} / \mathrm{lt}$ & $2.14(1.68-2.72)$ & $<.0001$ & $2.38(1.86-3.06)$ & $<.0001$ \\
ALT $\geq 25 \mathrm{u} / \mathrm{lt}$ & $1.31(1.06-1.61)$ & $=.0098$ & $1.19(0.91-1.56)$ & $\mathrm{n} . \mathrm{s}$ \\
\hline
\end{tabular}

$C V D$ cardio vascular disease (any among ischemic heart disease, heart failure, AF, stroke), AST aspartate aminotransferase, $A L T$ alanine aminotransferase

PROPORTION OF OUTCOMES PER CLASS OF TREATMENT

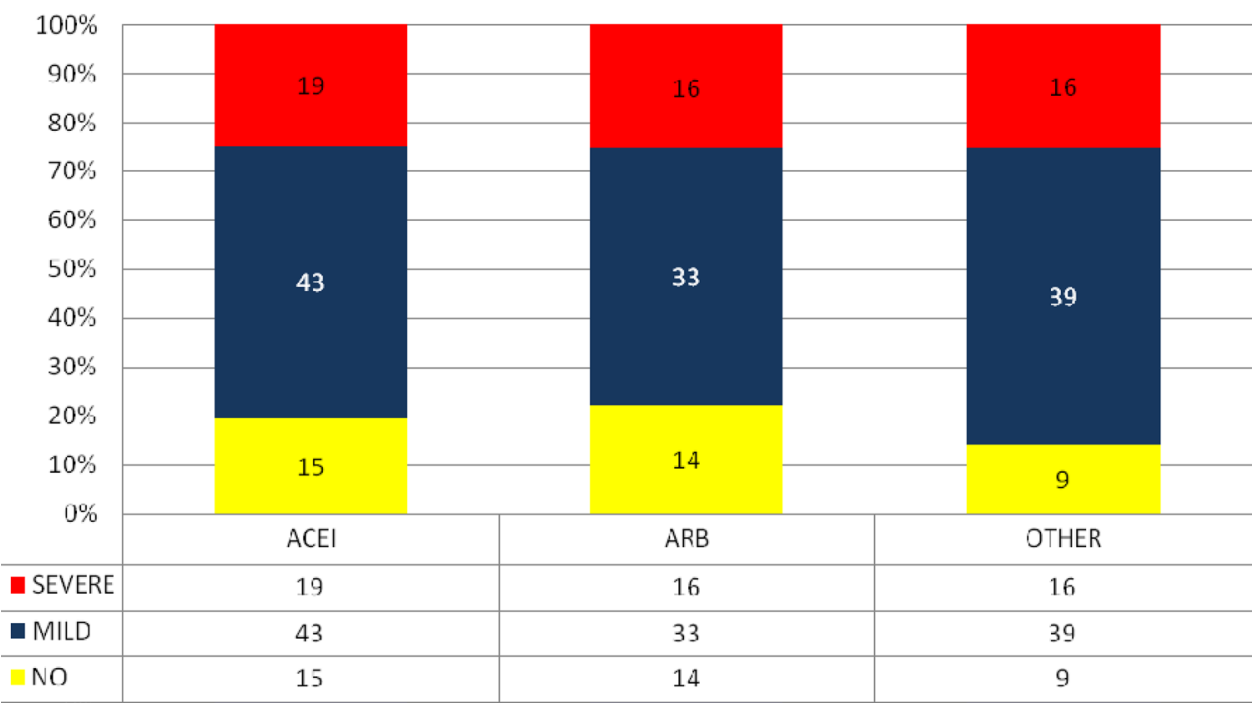

\begin{tabular}{lrlllllll}
\hline & \multicolumn{1}{l}{$B$} & ES & Wald & $d f$ & Sig. & OR & \multicolumn{2}{l}{ 95\% CI } \\
\cline { 6 - 9 } & & & & & & & Lower & Upper \\
\hline Age & 0.029 & 0.012 & 5.445 & 1 & 0.020 & 1.029 & 1.005 & 1.054 \\
Lymphocyte count & -.001 & 0.000 & 6.316 & 1 & 0.012 & 0.999 & 0.999 & 1.000 \\
Creatinine & 1.070 & 0.610 & 3.083 & 1 & 0.079 & 2.917 & 0.883 & 9.634 \\
AST & 0.018 & 0.006 & 7.428 & 1 & 0.006 & 1.018 & 1.005 & 1.031 \\
CRP & 0.014 & 0.003 & 17.723 & 1 & 0.000 & 1.014 & 1.008 & 1.021 \\
CVD & 0.845 & 0.576 & 2.153 & 1 & 0.142 & 0.430 & 0.139 & 1.328 \\
Diabetes & 0.391 & 0.536 & 0.532 & 1 & 0.466 & 1.478 & 0.517 & 4.225 \\
Hypertension & 0.420 & 0.321 & 1.710 & 1 & 0.191 & 1.521 & 0.811 & 2.853 \\
Gender (male) & 0.174 & 0.335 & 0.270 & 1 & 0.603 & 1.190 & 0.617 & 2.294 \\
Constant & -2.647 & 1.236 & 4.586 & 1 & 0.032 & 0.071 & & \\
\hline
\end{tabular}


Table 4 Logistic regression analysis taking SEVERE RD as dependent variable

\begin{tabular}{|c|c|c|c|c|c|c|c|c|}
\hline & \multirow[t]{2}{*}{$B$} & \multirow[t]{2}{*}{ ES } & \multirow[t]{2}{*}{ Wald } & \multirow[t]{2}{*}{$d f$} & \multirow[t]{2}{*}{ Sig. } & \multirow[t]{2}{*}{ OR } & \multicolumn{2}{|c|}{$95 \% \mathrm{CI}$} \\
\hline & & & & & & & Lower & Upper \\
\hline AGE & 0.076 & 0.024 & 9.874 & 1 & 0.002 & 1.079 & 1.029 & 1.132 \\
\hline Lymphocyte count & 0.000 & 0.000 & 0.452 & 1 & 0.501 & 1.000 & 0.999 & 1.001 \\
\hline Creatinine & 2.348 & 1.050 & 4.998 & 1 & 0.025 & 10.468 & 1.336 & 82.031 \\
\hline AST & 0.016 & 0.011 & 2.097 & 1 & 0.148 & 1.016 & 0.994 & 1.039 \\
\hline CRP & 0.029 & 0.006 & 24.184 & 1 & 0.000 & 1.029 & 1.018 & 1.041 \\
\hline CVD & 1.510 & 0.834 & 3.277 & 1 & .070 & 0.221 & 0.043 & 1.133 \\
\hline Diabetes & 0.698 & 0.853 & 0.670 & 1 & 0.413 & 2.010 & 0.378 & 10.694 \\
\hline Hypertension & 0.473 & 0.671 & 0.496 & 1 & 0.481 & 0.623 & 0.167 & 2.323 \\
\hline Gender (male) & 0.103 & 0.691 & 0.022 & 1 & 0.881 & 1.109 & 0.286 & 4.295 \\
\hline Constant & -10.359 & 2.436 & 18.085 & 1 & 0.000 & 0.000 & & \\
\hline
\end{tabular}

\begin{tabular}{lrlrlllll}
\hline & \multicolumn{1}{c}{$B$} & & ES & Wald & $d f$ & Sig. & OR & \multicolumn{2}{l}{ 95\% CI } \\
\cline { 6 - 9 } & & & & & & & Lower & Upper \\
\hline Age & 0.130 & 0.021 & 38.614 & 1 & 0.000 & 1.139 & 1.093 & 1.187 \\
Lymphocyte count & -0.000 & 0.000 & 0.216 & 1 & 0.642 & 1.000 & 0.999 & 1.000 \\
Creatinine & 1.230 & 0.332 & 13.743 & 1 & 0.000 & 3.422 & 1.786 & 6.556 \\
AST & 0.000 & 0.001 & 0.232 & 1 & 0.630 & 1.000 & 0.999 & 1.002 \\
CRP & 0.005 & 0.002 & 4.387 & 1 & 0.036 & 1.005 & 1.000 & 1.010 \\
CVD & 0.481 & 0.373 & 1.662 & 1 & 0.197 & 0.618 & 0.297 & 1.285 \\
Diabetes & 0.119 & 0.452 & 0.069 & 1 & 0.793 & 1.126 & 0.464 & 2.731 \\
Hypertension & 0.520 & 0.413 & 1.585 & 1 & 0.208 & 0.595 & 0.265 & 1.336 \\
Gender (male) & 0.031 & 0.381 & 0.007 & 1 & 0.934 & 1.032 & 0.489 & 2.176 \\
Constant & -12.544 & 1.801 & 48.516 & 1 & 0.000 & 0.000 & & \\
\hline
\end{tabular}

Table 5 Logistic regression analysis taking DEATH as dependent variable hypertension was by far the more frequent comorbidity, with 221/431 affected individuals, a sample size suitable for meaningful comparisons.

By stratifying patients in three levels of clinical severity, we compared the proportion of each class of drugs in each severity class and the other way around the proportion of each severity class in each class of drugs. The main finding was that there was not even the least hint that ACEIs or ARBs behave differently from OTHERs in terms of increased frequency of worse outcomes. Their relative frequency was the same, about $20 \%$, among both MILD RD and SEVERE RD patients. Likewise, the proportion of patients evolving toward MILD or SEVERE RD was exactly the same in the three therapeutic classes (see Table 1 and Fig. 1). We believe this is a clear demonstration that on clinical grounds ACEIs and ARBs are in no way involved in enhancing the infectivity of SARS-CoV-2 and as a consequence, there is no reason why they should be withheld. Our findings confirm the results of a previous study performed on a much smaller sample [19]. As a corollary to the findings discussed above, it is worth noticing that when corrected for age and CVD, hypertension was no longer significant as a predictor of bad outcome. Indeed it is difficult to understand why adequately treated hypertension should adversely affect an infectious disease with respiratory target. Therefore, we would suggest that not so much hypertension but rather other factors usually correlated to hypertension such as age and established CVD offer a biologically more plausible explanation.

In univariate analyses, the relative risk of MILD RD and SEVERE RD increased by a factor of 2-16 with age, male gender, BMI, hypertension, renal failure and CVD, in agreement with most earlier reports [1, 3, 5, 12-14, 17]. Not surprisingly also markers of multiple organ failure, such as elevated creatinine and AST, or markers of hyperimmune response such as CRP were positively correlated to worse outcome. Indeed, CRP was the single most powerful predictor of outcome, linearly increasing from NO RD to MILD RD to SEVERE RD in a way that allowed the establishment of a threshold for SEVERE RD, with a good tradeoff of $87 \%$ sensitivity and $88.8 \%$ specificity.

Many of the individual predictors turned out to be intercorrelated and were excluded by logistic regression analysis, which retained only age, creatinine and CRP as independent predictors of SEVERE RD and DEATH. Creatinine levels, although systematically measured in earlier 
papers, have never been adequately emphasized as important markers [22]. Of note, in our cohort chronic renal failure was recorded in $4 \%(16 / 431)$ of patients on presentation, whereas the proportion of patients with actual creatinine levels above threshold was overall $30 \%$ with a distribution that proportionally increased from NO RD to SEVERE RD (Table 1). Reasons for this finding may depend on a selective vulnerability of kidney to coronavirus, possibly due to a large representation of ACE2, on vascular impairment (pre-existing or caused by vasculitis) or both $[6,16]$.

An important missing data in the present study is D-Dimer and Troponin T, important markers of the coagulopathy and silent myocardial damage that are increasingly being recognized in COVID-19 [23-26]. This occurred partly for a reduced awareness of the problem at the beginning of the study and partly because our interest was focused on antihypertensive treatment. Whether this flaw may have had an impact on the ascertainment of the cause of death is unknown. We did not record the certificate of death, and it is possible that a proportion of patients died of pulmonary embolism or of myocardial failure, but we believe this does not affect our results given the primary aim of the study.

In conclusion, we studied prospectively a cohort of consecutive Emergency Department patients found to have COVID-19 and were able to assess the relationship between ACEI and ARB use and the severity of the disease. Our findings rule out any effect of ACEI or ARB on prognosis [27]. Although many clinical variables had an individual effect on outcome, age, creatinine and CRP were the only independent predictors of SEVERE RD and DEATH.

Limitations of the study are the single centre nature, the limited time span of enrolment and the inability to collect important laboratory data. Strengths are the prospective enrolment and the direct assessment "on field" of all included patients.

Acknowledgements Gian Paolo Anzola, Clara Bartolaminelli, Gina Alessandra Gregorini and Chiara Coazzoli wish to publicly manifest their admiration and gratitude toward all the health professionals in the Emergency Department of the Gavardo Hospital who struggle daily against COVID-19 to look after patients at the risk of their own lives.

Funding The study was performed on a voluntary basis by all the authors.

\section{Compliance with ethical standards}

Conflict of interest All authors declare that they have no conflict of interest.

Ethics approval The study was approved by the local institutional review board.
Availability of data and material Clinical data are stored in the electronic files of the Gavardo Hospital.

Code availability None.

\section{References}

1. Guan WJ, Ni ZY, Hu Y et al (2020) Clinical characteristics of coronavirus disease 2019 in China. N Engl J Med. https://doi. org/10.1056/NEJMoa2002032

2. Donnelly CA, Ghani AC, Leung GM et al (2003) Epidemiological determinants of spread of causal agent of severe acute respiratory syndrome in Hong Kong. Lancet 361:1761-1766

3. Zhou F, Yu T, Du R et al (2020) Clinical course and risk factors for mortality of adult inpatients with COVID-19 in Wuhan, China: a retrospective cohort study. Lancet 395:1054-1062. https://doi.org/10.1016/S0140-6736(20)30566-3

4. Wu Z, McGoogan JM (2020) Characteristics of and important lessons from the coronavirus disease 2019 (COVID-19) outbreak in China: summary of a report of 72314 cases from the Chinese Center for Disease Control and Prevention. JAMA. https://doi.org/10.1001/jama.2020.2648

5. Wu C, Chen X, Cai Y et al (2020) Risk factors associated with acute respiratory distress syndrome and death in patients with coronavirus disease 2019 pneumonia in Wuhan, China. JAMA Intern Med. https://doi.org/10.1001/jamainternmed.2020.0994

6. Danser AHJ, Epstein M, Batlle D (2020) Renin-angiotensin system blockers and the COVID-19 pandemic: at present there is no evidence to abandon Renin-Angiotensin system blockers. Hypertension. https://doi.org/10.1161/HYPERTENSIONAHA .120 .15082

7. Li G, Rui Hu, Zhang X (2020) Antihypertensive treatment with ACEI/ARB of patients with COVID-19 complicated by hypertension. Hypertens Res. https://doi.org/10.1038/s4144 0-020-0433-1

8. Vaduganathan M, Vardeny O, Michel T et al (2020) Renin-Angiotensin-Aldosterone system inhibitors in patients with Covid-19. N Engl J Med. https://doi.org/10.1056/NEJMsr2005760

9. Fang L, Karakiulakis G, Roth M (2020) Are patients with hypertension and diabetes mellitus at increased risk for COVID-19 infection? Lancet Respir Med. https://doi.org/10.1016/S2213 $-2600(20) 30116-8$

10. Brown JD (2020) Antihypertensive drugs and risk of COVID19. Lancet Respir Med. https://doi.org/10.1016/S2213 -2600(20)30158-2

11. Heshui S, Xiaoyu H, Nanchuan J et al (2020) Radiological findings from 81 patients with COVID-19 pneumonia in Wuhan, China: a descriptive study. Lancet Infect Dis. https://doi. org/10.1016/S1473-3099(20)30086-4

12. Wan S, Xiang Y, Fang W et al (2020) Clinical features and treatment of COVID-19 patients in northeast Chongqing. J Med Virol. https://doi.org/10.1002/jmv.25783

13. Zhang JJ, Dong X, Cao YY et al (2020) Clinical characteristics of 140 patients infected with SARS-CoV-2 in Wuhan. Allergy. https://doi.org/10.1111/all.14238

14. Wang L, He W, Yu X et al (2020) Coronavirus disease 2019 in elderly patients: characteristics and prognostic factors based on 4-week follow-up. J Infect. https://doi.org/10.1016/j. jinf.2020.03.019

15. Grasselli G, Zangrillo A, Zanella A et al (2020) Baseline characteristics and outcomes of 1591 patients infected With SARSCoV-2 admitted to ICUs of the Lombardy Region, Italy. JAMA. https://doi.org/10.1001/jama.2020.5394 
16. Touyz RM, Li H, Delles C (2020) ACE2 the Janus-faced protein-from cardiovascular protection to severe acute respiratory syndrome-coronavirus and COVID-19. Clin Sci 134:747-750. https://doi.org/10.1042/CS20200363

17. Zheng YY, Ma YT, Zhang JY, Xie X (2020) COVID-19 and the cardiovascular system. Nat Rev Cardiol. https://doi.org/10.1038/ s41569-020-0360-5

18. Fang L, Karakiulakis G, Roth M (2020) Antihypertensive drugs and risk of COVID-19? - authors' reply. Lancet Respir Med. https ://doi.org/10.1016/S2213-2600(20)30159-4

19. Meng J, Xiao G, Zhang J et al (2020) Renin-angiotensin system inhibitors improve the clinical outcomes of COVID-19 patients with hypertension. Emerg Microbes Infect. https://doi. org/10.1080/22221751.2020.1746200

20. Tignanelli CJ, Ingraham NE, Sparks MA et al (2020) Antihypertensive drugs and risk of COVID-19? Lancet Respir Med. https ://doi.org/10.1016/S2213-2600(20)30153-3

21. Lo KB, McCullough PA, Rangaswami J (2020) Antihypertensive drugs and risk ofCOVID-19? Lancet Respir Med. https://doi. org/10.1016/S2213-2600(20)30156-9

22. Emami A, Javanmardi F, Pirbonyeh AA (2020) Prevalence of underlying diseases in hospitalized patients with COVID-19: a systematic review and meta-analysis. Arch Acad Emerg Med $8(1): \mathrm{e} 35$
23. Guo T, Fan Y, Chen M et al (2020) Cardiovascular implications of fatal outcomes of patients with Coronavirus Disease 2019 (COVID-19). JAMA Cardiol. https://doi.org/10.1001/jamacardio .2020.1017

24. Karbalai Saleh S, Oraii A, Soleimani A et al (2020) The association between cardiac injury and outcomes in hospitalized patients with COVID-19. Intern Emerg Med. https://doi.org/10.1007/ s11739-020-02466-1

25. Tang N, Li D, Wang X, Sun Z (2020) Abnormal coagulation parameters are associated with poor prognosis in patients with novel coronavirus pneumonia. J Thromb Haemost. https://doi. org/10.1111/jth. 14768

26. Giorgi-Pierfranceschi M, Paoletti O, Pan A et al (2020) Prevalence of asymptomatic deep vein thrombosis in patients hospitalized with SARS-CoV-2 pneumonia: a cross-sectional study. Intern Emerg Med. https://doi.org/10.1007/s11739-020-02472-3

27. Sarzani R, Giulietti F, Di Pentima C et al (2020) Antagonizing the renin-angiotensin-aldosterone system in the era of COVID19. Intern Emerg Med 15:885-887. https://doi.org/10.1007/s1173 9-020-02365-5

Publisher's Note Springer Nature remains neutral with regard to jurisdictional claims in published maps and institutional affiliations. 